\title{
Does Physical Protection of Soil Organic Matter Attenuate Temperature Sensitivity?
}

\author{
Alain F. Plante* \\ Dep. of Earth \& Environmental Sciences \\ Univ. of Pennsylvania \\ Philadelphia, PA 19104-6316

\section{Johan Six \\ Dep. of Plant Sciences \\ Univ. of California \\ Davis, CA 95616}

\section{Eldor A. Paul \\ Richard T. Conant \\ Natural Resource Ecology Lab. \\ Colorado State Univ. \\ Fort Collins, CO 80523-1499}

\begin{abstract}
Global climate change may induce accelerated soil organic matter (SOM) decomposition through increased soil temperature, and thus impact the $\mathrm{C}$ balance in soils. We hypothesized that compartmentalization of substrates and decomposers in the soil matrix would decrease SOM sensitivity to temperature. We tested our hypothesis with three short-term laboratory incubations with differing physical protection treatments conducted at different temperatures. Overall, $\mathrm{CO}_{2}$ efflux increased with temperature, but responses among physical protection treatments were not consistently different. Similar respiration quotient $\left(Q_{10}\right)$ values across physical protection treatments did not support our original hypothesis that the largest $Q_{10}$ values would be observed in the treatment with the least physical protection. Compartmentalization of substrates and decomposers is known to reduce the decomposability of otherwise labile material, but the hypothesized attenuation of temperature sensitivity was not detected, and thus the sensitivity is probably driven by the thermodynamics of biochemical reactions as expressed by Arrhenius-type equations.
\end{abstract}

Abbreviations: SOM, soil organic matter.
$S^{\circ}$ oil organic matter decomposition, and the resultant $\mathrm{CO}_{2}$ respiration, is a crucial part of the global $\mathrm{C}$ cycle, as it has a significant impact on atmospheric $\mathrm{CO}_{2}$ levels. Global climate change may induce an acceleration of SOM decomposition through increased soil temperature, and thus significantly impact the C balance in soils (Davidson and Janssens, 2006). Intensive study, however, has revealed variability in the response of soil respiration to temperature and spurned much debate in the literature (e.g., Davidson et al., 2006; Fang et al., 2006; Kirschbaum, 2006; Reichstein et al., 2005). Soil organic matter decomposition has often been described as a set of exclusively biochemical processes, and thus the temperature sensitivity relationships developed by Arrhenius and van't Hoff in the late 19th century have been applied extensively to soil respiration (e.g., Lloyd and Taylor, 1994). It is well established, however, that SOM is not stabilized in soils exclusively by biochemical recalcitrance (Marschner et al., 2008). While the temperature sensitivity of SOM stabilized by biochemical recalcitrance or sorption reactions to mineral surfaces might logically be subject to temperature sensitivities based on the thermodynamics of sorption and enzymatic reactions (e.g., Bosatta and Ågren, 1999), the temperature sensitivity of physically protected SOM

Soil Sci. Soc. Am. J. 73:1168-1172

doi:10.2136/sssaj2008.0351

Received 31 Oct. 2008.

*Corresponding author (aplante@sas.upenn.edu).

(c) Soil Science Society of America

677 S. Segoe Rd. Madison WI 53711 USA

All rights reserved. No part of this periodical may be reproduced or transmitted in any form or by any means, electronic or mechanical, including photocopying, recording, or any information storage and retrieval system, without permission in writing from the publisher. Permission for printing and for reprinting the material contained herein has been obtained by the publisher. is less obvious and has not been tested. Physical protection by occlusion of SOM within aggregates and compartmentalization of substrates and decomposers prevents the substrate from coming into contact with organisms and enzymes. Under conditions where substrate and decomposer are physically separated, there is little to suggest that increased temperatures might increase decomposition. Consequently, the applicability of biochemically based models of temperature sensitivity (i.e., $Q_{10}$ ) in the case of a large contribution of compartmentalization by aggregation may be weak.

The temperature sensitivity of SOM decomposition in response to variations in compartmentalization by soil aggregation has not previously been investigated and is the purpose of the current study. The hypothesis we proposed was that increased compartmentalization of substrate and degrader by increased soil aggregation would decrease SOM sensitivity to temperature, evidenced by smaller $Q_{10}$ values in soils with greater physical protection. Three separate short-term laboratory incubations were performed to test the relationship between the temperature sensitivity of soil respiration and physical protection by either disrupting compartmentalization imparted by soil aggregation (Exp. 1 and 2) or by creating contrasting degrees of compartmentalization (Exp. 3). Our hypothesis was tested using whole soil subjected to three degrees of physical disruption (Exp. 1), isolated macroaggregates subjected to physical disruption (Exp. 2), and the location of organic substrate in reconstituted macroaggregates (Exp. 3). In Exp. 2, we also tested whether increased $\mathrm{CO}_{2}$ efflux with increased temperature was caused by either an increased microbial biomass or greater respiration by an unchanged biomass. 


\section{MATERIALS AND METHODS Sites and Sampling}

Soil was collected in July of 2006 and 2007 from the Russell Larson Agricultural Research Center of Pennsylvania State University in Rock Springs, PA ( $\left.40^{\circ} 43^{\prime} \mathrm{N}, 77^{\circ} 56^{\prime} \mathrm{W}\right)$. The soil is a Hagerstown silt loam (a fine, mixed, semiactive, mesic Typic Hapludalf), with a textural composition of $160 \mathrm{~g} \mathrm{~kg}^{-1}$ sand, $670 \mathrm{~g} \mathrm{~kg}^{-1}$ silt, and $170 \mathrm{~g} \mathrm{~kg}^{-1}$ clay in the top $10 \mathrm{~cm}$, and a total organic $\mathrm{C}$ concentration of $19.3 \mathrm{~g} \mathrm{C} \mathrm{kg}^{-1}$ soil. The area of sampling is an abandoned pasture that has been under orchard grass (Dactylis glomerata L.) for 8 to $10 \mathrm{yr}$, with no tillage or fertilization occurring during this period. Mean annual precipitation for the area is $975 \mathrm{~mm}$, and mean annual temperature is $9.7^{\circ} \mathrm{C}$. Forty-eight soil cores (5-cm height and diameter) were collected from the field, and a 5 -kg block of soil ( $\sim 10$-cm depth) was also collected using a shovel. The field-moist block of soil was first broken apart by hand to pass through a 4-mm sieve and then air dried. The intact cores were also allowed to air dry after some cores were sacrificed for field moisture content and bulk density determinations.

\section{Experiment 1: Incubation of Soil Core Materials}

The collected soil cores were divided into three groups to generate three physical protection treatments for laboratory incubation: one-third of the cores were unaltered and retained as intact, one-third were sieved $(<2 \mathrm{~mm})$, and the final one-third were subjected to crushing $(<75 \mu \mathrm{m})$ by mortar and pestle. Laboratory incubations were performed in constant-temperature incubators set to 15,25 , or $35^{\circ} \mathrm{C}$. Sieved ( $\sim 100$ g air-dry soil) and crushed samples ( $\sim 85$ g air-dry soil) were poured into $125-\mathrm{mL}$ plastic specimen cups and tapped down to maximize bulk density, making it similar to that observed in the field (1.1-1.3 $\left.\mathrm{g} \mathrm{cm}^{-3}\right)$. Intact soil cores $(\sim 150 \mathrm{~g}$ air-dry soil) were kept in their metal sampling rings and water was added slowly to each sample to achieve $\sim 55 \%$ water-filled pore space based on bulk density and total porosity determinations. Four replicates from each physical protection treatment underwent 1 wk of preincubation, and respiration measurements were subsequently taken daily for $15 \mathrm{~d}$. Samples were incubated in sealed 1-L canning jars containing a $10-\mathrm{mL}$ vial of water to minimize evaporation of water from the soil. The headspace of each jar was sampled using a syringe through a septum installed in the jar lids, and $\mathrm{CO}_{2}$ concentrations were determined using a LICOR 7000 infrared gas analyzer (LICOR Corp., Lincoln, NE). Jars were aerated every 3 to $4 \mathrm{~d}$ to prevent anoxic conditions and $\mathrm{CO}_{2}$ inhibition by opening the lids, blowing air across the opening using an electric fan for $1 \mathrm{~min}$, and immediately resampling.

\section{Experiment 2: Incubation of Isolated Macroaggregates}

The air-dried <4-mm bulk soil was dry sieved by hand on a stack of a $4-\mathrm{mm}$ sieve over a $2-\mathrm{mm}$ sieve. The material remaining on the 2-mm screen was retained as intact 2- to 4-mm macroaggregates, while the material that passed through the $2-\mathrm{mm}$ screen was discarded. A portion of the 2- to 4-mm macroaggregates was then crushed to pass a $500-\mu \mathrm{m}$ sieve. Four replicates ( $\sim 100 \mathrm{~g}$ air dry) from each of the intact and crushed macroaggregate samples were prepared for incubation at 15,25 , or $35^{\circ} \mathrm{C}$ as described above. Samples underwent 1 wk of preincubation and respiration measurements were subsequently taken for $14 \mathrm{~d}$.

After the 25 and $35^{\circ} \mathrm{C}$ incubations (samples from the $15^{\circ} \mathrm{C}$ incubation were inadvertently destroyed), samples were analyzed for microbial biomass $\mathrm{C}$ and $\mathrm{N}$ using the fumigation-direct extraction technique (Vance et al., 1987). Specific respiration was determined by dividing the amount of $\mathrm{CO}_{2}$ respired during the 2 -wk incubations by the amount of microbial biomass $\mathrm{C}$ measured at the end of the same period (Anderson and Domsch, 1985; Santruckova and Straskraba, 1991).

\section{Experiment 3: Incubation of Reconstituted Macroaggregates}

Reconstituted macroaggregates were prepared in a manner similar to Bartlett and Doner (1988) by dispersing the sampled bulk soil in a $2: 1$ soil/water paste, which was allowed to dry until the soil was most friable (generally $23 \%$ moisture by mass). The partially dried paste was broken up by hand over a sieve stack to isolate the 2- to 4-mm macroaggregates. Two compartmentalization treatments were prepared: (i) ${ }^{13} \mathrm{C}$-enriched wheat (Triticum aestivum L.) residue located inside reconstituted macroaggregates by adding the residue $(<150-\mu \mathrm{m}$ particle size) to the $2: 1$ paste at a rate of $1.7 \mathrm{~g}$ straw $\mathrm{kg}^{-1}$ soil, and (ii) ${ }^{13} \mathrm{C}$-enriched wheat residue located outside macroaggregates by adding an equivalent amount of residue to air-dry reconstituted aggregates. Reconstituted macroaggregates with no added residue were used as a control. Analysis of the $\delta^{13} \mathrm{C}$ signatures of several individual aggregates presumed to contain the ${ }^{13} \mathrm{C}$-enriched wheat straw confirmed the presence of the label (data not shown). Four replicates $(\sim 50 \mathrm{~g}$ air dry) of each treatment were prepared for incubation at 25 or $35^{\circ} \mathrm{C}$ as described above. Samples underwent $1 \mathrm{wk}$ of preincubation and respiration measurements were subsequently taken for $30 \mathrm{~d}$.

Analyses of the isotopic signature of the respired $\mathrm{CO}_{2}\left(\delta^{13} \mathrm{CO}_{2}\right)$ were performed after 2, 9, and $30 \mathrm{~d}$ of incubation by injection of $250 \mu \mathrm{L}$ of headspace gas into a Thermo TRACE-GC gas chromatograph (Thermo Fisher Scientific, Waltham, MA) equipped with a Varian Poroband-Q 25-m column (Varian Inc., Palo Alto, CA), coupled to a Thermo-Finnigan Delta+ isotope ratio mass spectrometer. The proportion of respired $\mathrm{CO}_{2}$ derived from the labeled residue was determined using a standard mixing model where endpoint $\delta^{13} \mathrm{C}$ signatures were $721.6 \pm 4.8 \%$ o (mean \pm standard deviation) for the ${ }^{13} \mathrm{C}$-enriched wheat straw and $-23.6 \pm 0.8 \%$ o for respiration from the unamended soil.

\section{Temperature Sensitivity}

The temperature sensitivity of SOM dynamics during these short incubations is expressed using respiration quotients $\left(Q_{10}\right)$, which were determined by plotting the log of the cumulative respiration (because of the exponential relationship between temperature and respiration [e.g., Lloyd and Taylor, 1994]) as a function of incubation temperature for each replicate. The equation for the best-fitting linear regression for each treatment was then used to estimate the cumulative respiration at 25 and $35^{\circ} \mathrm{C}$. The value of $Q_{10}$ was determined by dividing regression-based estimates for cumulative $\mathrm{CO}_{2}$ respired at the higher temperature by the estimate for cumulative $\mathrm{CO}_{2}$ respired at the lower temperature.

\section{Statistical Analyses}

Experimental data were analyzed using two-way ANOVA procedures with SigmaStat (Systat Software Inc., Point Richmond, CA), with physical protection treatment and incubation temperature as the two main factors in the model. Separation of means was tested on significant main factors using Tukey's significant difference test. 


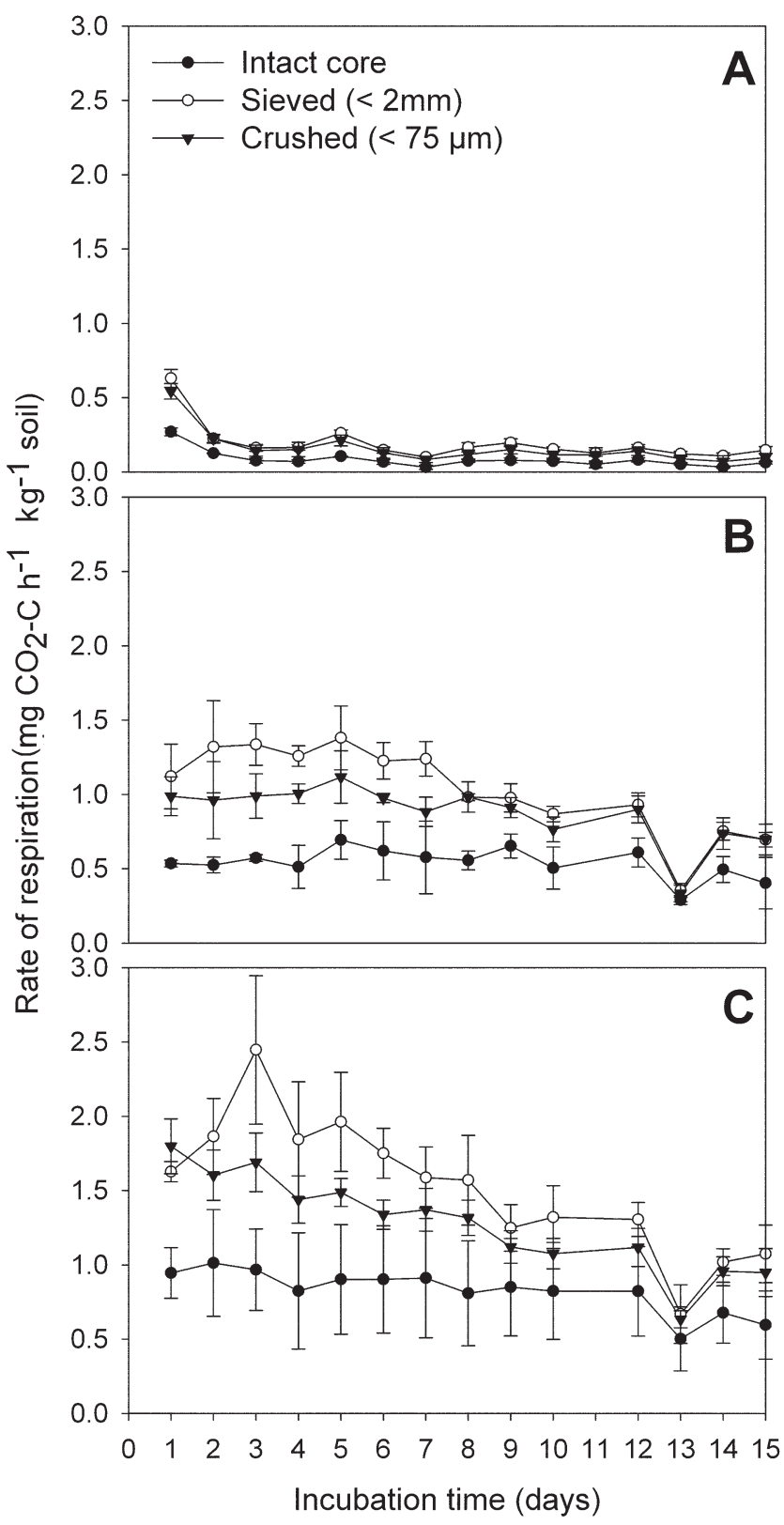

Fig. 1. Rates of soil respiration during incubation of soil core materials at (A) $15^{\circ} \mathrm{C},(B) 25^{\circ} \mathrm{C}$, and (C) $35^{\circ} \mathrm{C}$ in Exp. 1. Error bars represent standard deviations $(n=4)$.

\section{RESULTS}

Respiration rates during the incubation of intact, sieved, and crushed soil (Exp. 1) increased with increasing incubation temperature (Fig. 1). While relatively constant at 15 and $25^{\circ} \mathrm{C}$, the rates showed a slight downward trend during incubation at $35^{\circ} \mathrm{C}$, suggesting a depletion of labile substrates at this temperature. Similar results were observed in Exp. 2 and 3 with isolated and reconstituted macroaggregates (data not shown). For each of the three incubation experiments, cumulative $\mathrm{CO}_{2}$ respiration also increased significantly $(P<0.001$ in each experiment) with increasing incubation temperature (Table 1$)$. The response of cumulative $\mathrm{CO}_{2}$ respiration to the physical disruption and compartmentalization treatments differed among the experiments (Table 1). Physical disruption treatments $(P<0.001)$ and the interaction with temperature $(P=0.005)$ were significantly different in Exp. 1. In Exp. 2, cumulative $\mathrm{CO}_{2}$ did not differ between intact and crushed macroaggregates $(P=0.606)$, with a statistically significant interaction $(P=0.036)$. Cumulative $\mathrm{CO}_{2}$ respiration during Exp. 3 differed significantly between wheat residue amendment treatments $(P=0.019)$, with no statistically significant interaction with temperature $(P=0.770)$. While the overall residue location treatment effect was significant in the ANOVA, pairwise comparisons revealed that the inside vs. outside treatments were not significantly different $(P=0.335)$.

The temperature sensitivity of soil respiration, as expressed by respiration quotients $\left(Q_{10}\right)$, was not significantly different among the physical protection treatments in Exp. $1(P=0.874)$, was only slightly greater for intact vs. crushed macroaggregates in Exp. $2(P=0.090)$, and was not significantly different between the amendment treatments in Exp. $3(P=0.911)$ (Table 2).

Microbial biomass $\mathrm{C}$ and specific respiration were determined at the end of Exp. 2 to test for a potential cause for increased $\mathrm{CO}_{2}$ efflux with increased temperature. Microbial biomass $\mathrm{C}$ was significantly greater $(P<0.001)$ at 35 than $25^{\circ} \mathrm{C}$ (Table 3$)$, and was also significantly greater $(P=0.011)$ in intact macroaggregates than crushed macroaggregates (Table 3 ). The interaction term of the ANOVA was not statistically significant $(P=0.942)$. Specific respiration (kg respired $\mathrm{C} \mathrm{kg}^{-1}$ microbial biomass $\mathrm{C}[\mathrm{MBC}]$, Table 3$)$ was significantly greater $(P<0.001)$ after incubation at $25^{\circ} \mathrm{C}\left(\mathrm{LS}\right.$ mean $\left.=0.637 \mathrm{~kg} \mathrm{C} \mathrm{kg}^{-1} \mathrm{MBC}\right)$ than after incubation at $35^{\circ} \mathrm{C}\left(\mathrm{LS}\right.$ mean $\left.=0.505 \mathrm{~kg} \mathrm{C} \mathrm{kg}^{-1} \mathrm{MBC}\right)$, but did not differ between physical protection treatments $(P=0.064)$, with no statistically significant interaction $(P=0.134)$.

Table 1. Cumulative $\mathrm{CO}_{2}$ respiration during incubation of various physical protection treatments at three temperatures (mean \pm standard deviation).

\begin{tabular}{|c|c|c|c|c|c|}
\hline \multirow{2}{*}{ Experiment } & \multirow{2}{*}{ Treatment } & \multicolumn{4}{|c|}{ Cumulative $\mathrm{CO}_{2}$ respiration } \\
\hline & & $15^{\circ} \mathrm{C}$ & $25^{\circ} \mathrm{C}$ & $35^{\circ} \mathrm{C}$ & Meant \\
\hline \multirow{4}{*}{ 1: Soil core material $(15 \mathrm{~d}, n=4)$} & & & mg CC & $\mathrm{C} \mathrm{kg}^{-1}$ soil & \multirow[b]{2}{*}{168.1} \\
\hline & intact & $30.1 \pm 3.6$ & $179.3 \pm 39.7$ & $295.0 \pm 106$ & \\
\hline & sieved $(<2 \mathrm{~mm})$ & $69.0 \pm 6.8$ & $368.3 \pm 28.1$ & $543.4 \pm 53.0$ & 326.9 \\
\hline & crushed $(<75 \mu \mathrm{m})$ & $57.2 \pm 10.7$ & $315.6 \pm 27.0$ & $442.4 \pm 23.4$ & 271.9 \\
\hline \multirow{2}{*}{$\begin{array}{l}\text { 2: Isolated macroaggregates }(14 \mathrm{~d} \text {, } \\
n=5)\end{array}$} & intact $(2-4 \mathrm{~mm})$ & $147.3 \pm 7.2$ & $234.3 \pm 8.7$ & $263.6 \pm 13.8$ & 215.1 \\
\hline & crushed $(<500 \mu \mathrm{m})$ & $162.8 \pm 6.0$ & $237.8 \pm 8.8$ & $251.2 \pm 18.4$ & 217.3 \\
\hline \multirow{3}{*}{$\begin{array}{l}\text { 3: Reconstituted macroaggregates } \\
(30 \mathrm{~d}, n=4)\end{array}$} & no amendment & - & $921.2 \pm 123.9$ & $1224.5 \pm 64.1$ & 1073 \\
\hline & amendment inside & - & $1059.6 \pm 113.5$ & $1430.0 \pm 95.4$ & 1245 \\
\hline & amendment outside & - & $1015.4 \pm 114.2$ & $1315.1 \pm 131.3$ & 1165 \\
\hline
\end{tabular}

† Least square mean across temperatures; $\mathrm{SE}=14.2$ in Exp. 1, 10.1 in Exp. 2, 38.7 in Exp. 3. 
Stable isotope signatures of the respired $\mathrm{CO}_{2}$ were measured in Exp. 3 to determine the relative decomposition of the added substrate. The $\delta^{13} \mathrm{CO}_{2}$ values were significantly greater $(P<0.001)$ at 25 than $35^{\circ} \mathrm{C}$ (Table 4). Across both incubation temperatures, differences in $\delta^{13} \mathrm{CO}_{2}$ values due to the residue location treatments declined during the experiment. While the $\delta^{13} \mathrm{CO}_{2}$ values for amended vs. unamended samples remained statistically different throughout the experiment, differences between inside vs. outside of macroaggregates were significant only at the first measurement $(P<0.001$ at Day $2, P=$ 0.199 at Day 9 , and $P=0.766$ at Day 30$)$.

\section{DISCUSSION AND CONCLUSIONS}

Experimental evidence for the physical protection of SOM in macroaggregates has come from a number of experiments that have shown increased $\mathrm{C}$ and $\mathrm{N}$ mineralization with crushing, particularly in cultivated soils (as reviewed by Balesdent et al., 2000; Six et al., 2002); however, not all experiments have demonstrated similar results (Franzluebbers, 1999; GarciaOliva et al., 2004; Pulleman and Marinissen, 2004; Stenger et al., 2002). We suspect that the physical disruption treatments used in our experiments may have been insufficient to release large amounts of physically protected SOM for decomposition. There is some evidence to suggest that disruption of microaggregates (grinding to $<50 \mu \mathrm{m}$ ) rather than macroaggregates (crushing to $<250 \mu \mathrm{m}$ ) is required to release SOM and observe an increase in respiration (Six et al., 2002). Conversely, the placement of residues inside of reconstituted macroaggregates should have increased respiration compared with residues placed outside of macroaggregates by reducing the compartmentalization of substrates and decomposers.

The lack of differences in the $Q_{10}$ values among physical disruption treatments does not support our original hypothesis that the largest $Q_{10}$ values would be observed in the treatment with the least physical protection. Soil aggregation is known to reduce the decomposability of otherwise labile material by physically separating the substrate from the microbial biomass and its enzymes (Oades, 1984). Beare et al. (1994) estimated that SOM physically protected in macroaggregates represented only 10 to $20 \%$ of the total mineralizable C and only $\sim 1 \%$ of total aggregate $\mathrm{C}$. If one also considers microaggregates (by crushing to smaller sizes), physical protection represents a greater proportion of total C, but still less than $\sim 5 \%$ (Six et al., 2002). The hypothesized attenuation of temperature sensitivity provided by physical protection may therefore be minor compared with the sensitivity imparted by biochemical thermodynamics as expressed by Arrhenius-type equations.

We also sought to determine a potential cause for the increased $\mathrm{CO}_{2}$ efflux with increased temperature. An increase in soil respiration due to increased temperature may be attributable to an increase in the size of the microbial biomass respiring at the same rate, or to an increase in
Table 3. Microbial biomass $C(M B C)$, microbial biomass $N(M B N), C / N$, and specific respiration (amount of $\mathrm{CO}_{2}-\mathrm{C}$ respired per unit of $\mathrm{MBC}$ ) for intact and crushed macroaggregates after incubation at two temperatures (mean \pm standard deviation, $n=5$ ).

\begin{tabular}{|c|c|c|c|c|c|}
\hline Treatment & $\begin{array}{l}\text { Incubation } \\
\text { temperature }\end{array}$ & MBC & MBN & $\begin{array}{l}\text { Microbial } \\
\mathrm{C} / \mathrm{N}\end{array}$ & Specific respiration \\
\hline \multirow{3}{*}{$\begin{array}{l}\text { Intact } 2-4 \mathrm{~mm} \\
\text { macroaggregates }\end{array}$} & ${ }^{\circ} \mathrm{C}$ & $\mathrm{mg} \mathrm{C} \mathrm{kg}^{-1}$ soil & $\mathrm{mg} \mathrm{N} \mathrm{kg}{ }^{-1}$ soil & & $\mathrm{kg} \mathrm{C}$ respired $\mathrm{kg}^{-1} \mathrm{MBC}$ \\
\hline & 25 & $389 \pm 35$ & $40 \pm 11$ & $10.2 \pm 1.9$ & $0.61 \pm 0.05$ \\
\hline & 35 & $526 \pm 20$ & $19 \pm 6$ & $29.1 \pm 7.6$ & $0.50 \pm 0.03$ \\
\hline \multirow{2}{*}{$\begin{array}{l}\text { Crushed }(<500 \mu \mathrm{m}) \\
\text { macroaggregates }\end{array}$} & 25 & $356 \pm 10$ & $39 \pm 6$ & $9.2 \pm 1.2$ & $0.67 \pm 0.03$ \\
\hline & 35 & $495 \pm 26$ & $21 \pm 6$ & $24.6 \pm 5.8$ & $0.51 \pm 0.05$ \\
\hline
\end{tabular}

specific respiration by an unchanged biomass, or some combination of the two. Our results suggest that increased respiration can be attributed to increased microbial biomass. Microbial biomass $\mathrm{C}$ was greater at $35^{\circ} \mathrm{C}$ than at $25^{\circ} \mathrm{C}$ and specific respiration was lower, meaning that the microbial populations were less efficient in their use of substrate and respired a greater amount of $\mathrm{CO}_{2}$ per unit biomass $\mathrm{C}$. While temperature dependence of total soil respiration is well established, much less is known about how that dependence affects different groups of microorganisms. Microbial biomass $\mathrm{C}$ and $\mathrm{N}$ data alone are clearly insufficient to determine changes in the microbial community composition and activity, and further studies in this area should be supported by community structure analyses as well as substrate utilization efficiency analyses.

We performed three tests of whether compartmentalization of substrate and decomposer through physical protection alters the short-term temperature sensitivity of SOM dynamics. Our three incubations of soil samples with varying degrees of physical disruption or compartmentalization showed no significant differences in $Q_{10}$. Based on these results, we conclude that physical protection of SOM is insufficient to attenuate the temperature sensitivity of decomposition, which may be driven by Arrhenius-like relationships due to biochemical phenomena. It remains important, however, to further test various nonbiochemical SOM protection mechanisms because even fractionally small changes in temperature sensitivity under changing climate can result in globally significant changes in soil C stocks.

\section{ACKNOWLEDGMENTS}

We would like to thank Dr. Curtis Dell, USDA-ARS Pasture Systems Watershed Management Research Unit, for assistance in coordination of field sampling; Dr. R. Kelman Weider, Department of Biology, Villanova University, for access to laboratory facilities; and Alexandra Kougentakis, Aslihan Sen, and Charles Slominski for laboratory 
Table 4. Isotopic signature of respired $\mathrm{CO}_{2}\left(\delta^{13} \mathrm{CO}_{2}\right)$ and proportion of residue-derived respiration during incubation of reconstituted macroaggregates containing ${ }^{13} \mathrm{C}$-labeled wheat straw (mean \pm standard deviation, $n=4$ ).

\begin{tabular}{|c|c|c|c|c|c|c|c|}
\hline \multirow{2}{*}{ Treatment } & \multirow{2}{*}{ Parameter } & \multicolumn{3}{|c|}{$25^{\circ} \mathrm{C}$} & \multicolumn{3}{|c|}{$35^{\circ} \mathrm{C}$} \\
\hline & & Day 2 & Day 9 & Day 30 & Day 2 & Day 9 & Day 30 \\
\hline No residue & $\delta^{13} \mathrm{CO}_{2}$ & $-23.3 \pm 2.6$ & $-23.7 \pm 0.6$ & $-24.8 \pm 0.8$ & $-22.96 \pm 0.3$ & $-23.9 \pm 0.3$ & $-23.2 \pm 0.2$ \\
\hline Residue inside & $\delta^{13} \mathrm{CO}_{2}$ & $274.6 \pm 20.6$ & $121.1 \pm 7.0$ & $90.2 \pm 22.3$ & $226.8 \pm 23.5$ & $89.3 \pm 4.4$ & $52.9 \pm 2.3$ \\
\hline macroaggregates & proportion of respiration, $\%$ & $40.0 \pm 2.8$ & $19.4 \pm 0.9$ & $15.4 \pm 3.0$ & $33.5 \pm 3.2$ & $15.2 \pm 0.6$ & $10.2 \pm 0.3$ \\
\hline Residue outside & $\delta^{13} \mathrm{CO}_{2}$ & $205.5 \pm 24.4$ & $118.5 \pm 6.7$ & $107.0 \pm 30.9$ & $187.9 \pm 29.7$ & $66.4 \pm 6.6$ & $42.4 \pm 6.1$ \\
\hline macroaggregates & proportion of respiration, \% & $30.7 \pm 3.3$ & $19.1 \pm 0.9$ & $14.1 \pm 7.9$ & $28.3 \pm 4.0$ & $12.1 \pm 0.9$ & $12.7 \pm 7.8$ \\
\hline
\end{tabular}

assistance. This project was supported by REU grants from NSF Division of Environmental Biology for A. Kougentakis and A. Sen, a Penn Provost's Undergraduate Research Mentorship Award for C. Slominski, and NSF Grant DEB0444880.

\section{REFERENCES}

Anderson, T.H., and K.H. Domsch. 1985. Determination of ecophysiological maintenance carbon requirements of soil microorganisms in a dormant state. Biol. Fertil. Soils 1:81-89.

Balesdent, J., C. Chenu, and M. Balabane. 2000. Relationship of soil organic matter dynamics to physical protection and tillage. Soil Tillage Res. 53:215-230.

Bartlett, J.R., and H.E. Doner. 1988. Decomposition of lysine and leucine in soil aggregates: Adsorption and compartmentalization. Soil Biol. Biochem. 20:755-759.

Beare, M.H., M.L. Cabrera, P.F. Hendrix, and D.C. Coleman. 1994. Aggregateprotected and unprotected organic matter pools in conventional tillage and no-tillage soils. Soil Sci. Soc. Am. J. 58:787-795.

Bosatta, E., and G.I. Ågren. 1999. Soil organic matter quality interpreted thermodynamically. Soil Biol. Biochem. 31:1889-1891.

Davidson, E.A., and I.A. Janssens. 2006. Temperature sensitivity of soil carbon decomposition and feedbacks to climate change. Nature 440:165-173.

Davidson, E.A., I.A. Janssens, and Y.Q. Luo. 2006. On the variability of respiration in terrestrial ecosystems: Moving beyond $Q_{10}$. Global Change Biol. 12:154-164.

Fang, C., P. Smith, and J.U. Smith. 2006. Is resistant soil organic matter more sensitive to temperature than the labile organic matter? Biogeosciences 3:65-68.

Franzluebbers, A.J. 1999. Potential C and $\mathrm{N}$ mineralization and microbial biomass from intact and increasingly disturbed soils of varying texture. Soil Biol. Biochem. 31:1083-1090.
Garcia-Oliva, F., M. Oliva, and B. Sveshtarova. 2004. Effect of soil macroaggregates crushing on $\mathrm{C}$ mineralization in a tropical deciduous forest ecosystem. Plant Soil 259:297-305.

Kirschbaum, M.U.F. 2006. The temperature dependence of organic-matter decomposition: Still a topic of debate. Soil Biol. Biochem. 38:2510-2518.

Lloyd, J., and J.A. Taylor. 1994. On the temperature dependence of soil respiration. Funct. Ecol. 8:315-323.

Marschner, B., S. Brodowski, A. Dreves, G. Gleixner, A. Gude, P.M. Grootes, et al. 2008. How relevant is recalcitrance for the stabilization of organic matter in soils? J. Plant Nutr. Soil Sci. 171:91-110.

Oades, J.M. 1984. Soil organic matter and structural stability: Mechanisms and implications for management. Plant Soil 76:319-337.

Pulleman, M.M., and J.C.Y. Marinissen. 2004. Physical protection of mineralizable $\mathrm{C}$ in aggregates from long-term pasture and arable soil. Geoderma 120:273-282.

Reichstein, M., T. Katterer, O. Andren, P. Ciais, E.D. Schulze, W. Cramer, D. Papale, and R. Valentini. 2005. Temperature sensitivity of decomposition in relation to soil organic matter pools: Critique and outlook. Biogeosciences 2:317-321.

Santruckova, H., and M. Straskraba. 1991. On the relationship between specific respiration activity and microbial biomass in soils. Soil Biol. Biochem. 23:525-532.

Six, J., C. Feller, K. Denef, S.M. Ogle, J.C.D. Sa, and A. Albrecht. 2002. Soil organic matter, biota and aggregation in temperate and tropical soils: Effects of no-tillage. Agronomie 22:755-775.

Stenger, R., G.F. Barkle, and C.P. Burgess. 2002. Mineralisation of organic matter in intact versus sieved/refilled soil cores. Aust. J. Soil Res. 40:149-160.

Vance, E.D., P.C. Brookes, and D.S. Jenkinson. 1987. An extraction method for measuring soil microbial biomass C. Soil Biol. Biochem. 19:703-707. 